Original Research Article

\title{
Evaluation of visual deficits in different types of amblyopia at rural tertiary setup
}

\author{
Dulani S. ${ }^{1}$, Diagavane S. ${ }^{2}$, Tibewal A. ${ }^{3}$
}

${ }^{1}$ Dr. Somya Dulani, Professor, Bharat Ratna Late Shree Atal Bihari Vajpayee Memorial Medical College, Rajnandgaon, Chhattisgarh, ${ }^{2}$ Dr. Sachin Diagavane, Professor, Jawaharlal Nehru Medical College Datta Meghe Institute of Medical Sciences (Deemed to be University), Wardha, Maharashtra, ${ }^{3}$ Dr. Anand Tibewal, Professor, Jawaharlal Nehru Medical College Datta Meghe Institute of Medical Sciences (Deemed to be University), Wardha, Maharashtra, India.

Corresponding Author: Dr. Somya Dulani, Professor, Bharat Ratna Late Shree Atal Bihari Vajpayee Memorial Medical College, Rajnandgaon, Chhattisgarh, India. E-mail: drsomya1010@gmail.com

\begin{abstract}
Introduction: Amblyopia is defined as unilateral or bilateral dimness of vision caused by form vision deprivation and/or abnormal binocular interaction, is the most common cause of preventable monocular blindness and nearly all-amblyopic visual loss is reversible with timely detection and appropriate intervention. The conditions leading to functional amblyopia are well known and include strabismus, anisometropia, astigmatism, hypermetropia, cataract, and other forms of stimulus deprivation. Material \& Method: The present hospital based cross sectional study has been carried out in Department of Ophthalmology at Acharya Vinoba Bhave Rural Hospital attached to Jawaharlal Nehru Medical College, Sawangi (Meghe), Wardha, a constituent of Datta Meghe Institute of Medical Sciences (Deemed University), Nagpur during the period from September 2012 to August 2014. 100 eyes of 91 patients having Amblyopia or amblyogenic factor (strabismus or anisometropia) in outdoor and indoor patients were selected for the study.All patients were enrolled in the study after due consideration of various exclusion criteria for selection. Results: The mean age of the study population was $15.00 \pm 5.74$ years, range 6-30 year. The present study found amblyopia to be more common in males than females. All the patients included in this study had one of the diagnoses from strabismic amblyopia, anisometropic amblyopia, isometropic amblyopia and stimulus deprivation amblyopia. Out of these maximum number of eyes was found to have anisometropic amblyopia (37\%) and strabismic amblyopia (36\%). Maximum numbers of eyes were seen with0.9-1.0 visual acuity (in LogMAR units). It was found to be highly significant in almost all except between strabismic and stimulus deprivation amblyopia; and between anisometropic and isometropic amblyopia. The present study found colour vision to be normal in all the various types of amblyopia. Most eyes were found to have hyperopic astigmatism/hyperopia (56\%) followed by myopic astigmatism/myopia (31\%) while mixed astigmatism was least common (13\%). Maximum numbers of eyes were seen with $0.00-0.15$ contrast sensitivity. $43 \%$ had normal while $57 \%$ had abnormal stereopsis. Conclusion: Amblyopia and associated strabismus can have devastating psychosocial and economic fallouts. Knowledge about the sub-types of amblyopia is important because the clinical presentations, management and outcomes of these different types are different. The data in the present study could be used to enhance screening efforts in an organized manner in those health-care groups which come in regular contact with infants and young children.
\end{abstract}

Keywords: Amblyopia, Anisometropic, Strabismic, Visual Acuity, Stereopsis

\section{Introduction}

Just as sunshine heralds the onset of happy bright day, normal visual acuity lays the foundation for binocular vision. It is therefore essential for a man is to have normal vision in both eyes [1]. Perhaps amblyopia, which is defined as unilateral or bilateral dimness of vision caused by form vision deprivation and/or abnormal binocular interaction, is the most common cause of preventable monocular blindness and nearly all-amblyopic visual loss is reversible

Manuscript received: $10^{\text {th }}$ December 2019

Reviewed: $\mathbf{2 0}^{\text {th }}$ December 2019

Author Corrected: $26^{\text {th }}$ December 2019

Accepted for Publication: 30 ${ }^{\text {th }}$ December 2019

Tropical Journal of Ophthalmology and Otolaryngology with timely detection and appropriate intervention. The conditions leading to functional amblyopia are well known and include strabismus, anisometropia, astigmatism, hypermetropia, cataract, and other forms of stimulus deprivation. Amblyopia is not a simple phenomenon. Along with the loss of Snellen and grating acuity, there may be loss of vernier acuity, loss of contrast sensitivity, distortions in the shape of a stimulus, some uncertainty about the position of a stimulus, motion deficits, and an increase in the magnitude of the crowding effect or separation difficulty [2-6]. 


\section{Original Research Article}

There are only a few studies which have prospectively evaluated the clinical profile of different sub-types of amblyopia along with the various visual deficits occurring in them [7].

This study was thus undertaken to evaluate the various visual deficits occurring in patients with amblyopia at a rural setup.

Aim: Evaluation of Visual Deficits in Amblyopia at Department of Ophthalmology at Acharya Vinoba Bhave Rural Hospital attached to Jawaharlal Nehru Medical College, Sawangi (Meghe), Wardha, a constituent of Datta Meghe Institute of Medical Sciences (Deemed University), Nagpur (M.H.), India.

\section{Objectives}

1. To identify the various types of amblyopia.

2. To study the magnitude of visual deficits in different types of amblyopia.

3. To study the relation of various visual deficits with the type of amblyopia.

\section{Methodology}

The present hospital based cross sectional study has been carried out in Department of Ophthalmology at Acharya Vinoba Bhave Rural Hospital attached to Jawaharlal Nehru Medical College, Sawangi (Meghe), Wardha, a constituent of Datta Meghe Institute of Medical Sciences (Deemed University), Nagpur during the period from September 2012 to August 2014.

Randomization was ensured as the patients were included in the study as they came in the eye OPD for check-up.

Sample Size: 100 eyes of 91 patients having Amblyopia or amblyogenic factor (strabismus or anisometropia) in outdoor and indoor patients

\section{Inclusion Criteria}

1) All patients with amblyopia.

2) All patients aged between 6 years to 30 years of age.

3) All patients with amblyogenic factors like strabismus or anisometropia.

\section{Exclusion Criteria}

1) Patients with ocular pathology (inflammatory and posterior segment diseases)
2) Patients who are mentally retarded.

3) Patients who had not given consent for study.

Method: All patients were enrolled in the study after due consideration of various exclusion criteria for selection.

Written explained consent about the type of study was obtained from the patient (parent/guardian) in the language that he understood the best.

Clinically amblyopia has been defined as unilateral or bilateral reduction in the best-corrected visual acuity caused by form vision deprivation and/or abnormal binocular interaction, without a visible organic cause commensurate with this visual loss.

A best corrected central visual acuity less than $20 / 40$ is labeled as bilateral amblyopia and a difference of two or more lines between normal and amblyopic eye is required to classify it as unilateral amblyopia [2].

Each patient's ophthalmic examination was done in the following way,

1. Visual acuity

2. Anterior segment examination

3. Colour vision

4. Contrast sensitivity

5. Crowding phenomenon

6. Fine motor skills

7. Stereopsis

8. Cycloplegic Refraction

9. Posterior segment examination

Statistical Analysis: Data was compiled in MS-Excel and checked for its completeness and correctness then the statistical software like SPSS version 17.0 and SYSTAT version 12.0 was used to analyze the data.

The statistical tests like chi square test, student ' $t$ ' test and analysis of variance (ANOVA) were used to test the significance difference at $95 \%$ confidence interval.

Statistical significance was tested at $5 \%$ level of significance. 


\section{Result}

Table-1: Age and Sex wise distribution of the study groups.

\begin{tabular}{|l|c|c|}
\hline Age group (years) & No of patients & Percentage \\
\hline $6-10$ & 21 & 23.07 \\
\hline $11-15$ & 34 & 25.27 \\
\hline $16-20$ & 23 & 6.59 \\
\hline $21-25$ & 6 & 7.69 \\
\hline $26-30$ & 7 & 100.00 \\
\hline Total & 91 & $15.00 \pm 5.74$ years \\
\hline Mean Age & \multicolumn{2}{|c|}{$6-30$ years } \\
\hline Range & No of patients & Percentage \\
\hline Gender & 52 & 57.14 \\
\hline Male & 39 & 42.86 \\
\hline Female & 91 & 100.00 \\
\hline Total & \multicolumn{2}{|c|}{} \\
\hline
\end{tabular}

The mean age of the study population was $15.00 \pm 5.74$ years, range 6-30 year. The present study found amblyopia to be more common in males than females (Table-1).

Table-2: Distribution of eyes on the basis of diagnosis.

\begin{tabular}{|l|c|c|c|c|}
\hline Diagnosis & No of eyes & Percentage (\%) & Chi- square & P-value \\
\hline b & 36 & 36.00 & & \\
\cline { 1 - 3 } Anisometropic Amblyopia & 37 & 37.00 & \multirow{2}{*}{22.8} & \multirow{2}{*}{$0.001^{*}$} \\
\hline Isometropic Amblyopia & 18 & 18.00 & \\
\hline Stimulus Deprivation Amblyopia & 9 & 9.00 & & \\
\hline Total & 100 & 100.00 & & \\
\hline
\end{tabular}

$* \mathrm{P}<0.05$, Significant

All the patients included in this study had one of the diagnoses from strabismic amblyopia, anisometropic amblyopia, isometropic amblyopia and stimulus deprivation amblyopia. Out of these maximum number of eyes was found to have anisometropic amblyopia (37\%) and strabismic amblyopia (36\%) (Table-2).

Table-3: Distribution of eyes according to visual acuity.

\begin{tabular}{|c|c|c|}
\hline $\begin{array}{c}\text { Visual Acuity } \\
\text { (LogMAR units) }\end{array}$ & No. of eyes & Percentage (\%) \\
\hline $0-0.2$ & 0 & 0.00 \\
\hline $0.3-0.4$ & 16 & 16.00 \\
\hline $0.5-0.6$ & 25 & 25.00 \\
\hline $0.7-0.8$ & 25 & 25.00 \\
\hline $0.9-1.0$ & 34 & 34.00 \\
\hline Total & 100 & 100.00 \\
\hline
\end{tabular}

The visual acuity in the present study was divided into five groups. Maximum numbers of eyes were seen with $0.9-1.0$ visual acuity (in LogMAR units) (Table-3), 
Table-4: Average visual acuity in various types of amblyopia

\begin{tabular}{|l|c|c|}
\hline Diagnosis & No of eyes & $\begin{array}{c}\text { Visual Acuity } \\
\text { (LogMAR units) } \\
\text { Mean } \pm \text { S.D }\end{array}$ \\
\hline Strabismic Amblyopia & 36 & $0.76 \pm 0.19$ \\
\hline Anisometropic Amblyopia & 37 & $0.65 \pm 0.19$ \\
\hline Isometropic Amblyopia & 18 & $0.61 \pm 0.25$ \\
\hline Stimulus Deprivation Amblyopia & 9 & $0.87 \pm 0.19$ \\
\hline F test & \multicolumn{2}{|c|}{4.72} \\
\hline p value & $0.004 *$ (Highly significant) \\
\hline
\end{tabular}

$* \mathrm{P}<0.05$, significant

The visual acuity of all eyes included in the present study was taken and the average visual acuity in each group was determined (Table-4).

Table-5: Mean difference among the diagnosis: visual acuity.

\begin{tabular}{|l|c|c|c|c|}
\hline \multirow{2}{*}{ Diagnosis } & \multicolumn{3}{|c|}{ Mean difference among the Diagnosis: Visual Acuity } \\
\cline { 2 - 5 } & $\begin{array}{c}\text { Strabismic } \\
\text { Amblyopia }\end{array}$ & $\begin{array}{c}\text { Anisometropic } \\
\text { Amblyopia }\end{array}$ & $\begin{array}{c}\text { Isometropic } \\
\text { Amblyopia }\end{array}$ & $\begin{array}{c}\text { Stimulus Deprivation } \\
\text { Amblyopia }\end{array}$ \\
\hline Strabismic Amblyopia & - & $0.11 *$ & $0.14 *$ \\
$(\mathrm{p}$ value $=0.003)$ & $(\mathrm{p}$ value $=0.017)$ & 0.11 \\
& & & 0.04 & $0.22 *$ \\
Anisometropic Amblyopia & - & & & $(\mathrm{p}$ value $=0.09)$ \\
\hline Isometropic Amblyopia & & & & $0.26 * 0.005)$ \\
\hline $\begin{array}{l}\text { Stimulus } \\
\text { Amblyopia }\end{array}$ & & & & $(\mathrm{p}$ value $=0.003)$ \\
\hline
\end{tabular}

$* \mathrm{P}<0.05$, Significant

It was found to be highly significant in almost all except between strabismic and stimulus deprivation amblyopia; and between anisometropic and isometropic amblyopia (Table-5)

Table-6: Distribution of eyes according to colour vision $(n=100)$.

\begin{tabular}{|c|c|c|}
\hline Colour Vision & No of eyes & Percentage (\%) \\
\hline Normal & 100 & 100.00 \\
\hline Abnormal & 0 & 0.00 \\
\hline Total & 100 & 100.00 \\
\hline
\end{tabular}

The present study found colour vision to be normal in all the various types of amblyopia (Table-6). 
Original Research Article

Table-7: Distribution of eyes with presence or absence of crowding phenomenon in various types of amblyopia (n=100).

\begin{tabular}{|l|c|c|c|}
\hline Diagnosis & $\begin{array}{c}\text { Crowding } \\
\text { phenomenon present } \\
\text { (\% of eyes) }\end{array}$ & $\begin{array}{c}\text { Crowding } \\
\text { phenomenon absent } \\
\text { (\% of eyes) }\end{array}$ & $\begin{array}{c}\text { Chi Square } \\
\text { (P value) }\end{array}$ \\
\hline Strabismic Amblyopia (n=36) & $23(63.88 \%)$ & $13(36.11 \%)$ & $\begin{array}{c}2.77 \\
(0.096)^{*}\end{array}$ \\
\hline Anisometropic Amblyopia (n=37) & $13(35.13 \%)$ & $24(64.86 \%)$ & $\begin{array}{c}3.27 \\
(0.07)^{*}\end{array}$ \\
\hline Isometropic Amblyopia (n=18) & $6(33.33 \%)$ & $12(66.66 \%)$ & $\begin{array}{c}2.00 \\
(0.157)^{*}\end{array}$ \\
\hline Stimulus Deprivation Amblyopia (n=9) & $5(55.55 \%)$ & $4(44.44 \%)$ & $\begin{array}{c}0.11 \\
(0.737)^{*}\end{array}$ \\
\hline Total (n=100) & $47(47 \%)$ & $53(53 \%)$ & $\begin{array}{c}0.36 \\
(0.54)^{*}\end{array}$ \\
\hline
\end{tabular}

$* \mathbf{P}>\mathbf{0 . 0 5}$, Non-Significant

The crowding phenomenon was tested in the study group and according to presence or absence of crowding phenomenon; the eyes were divided into two groups. The effect of crowding was more in strabismic amblyopia as compared to the other types (Table-7).

Table-8: Distribution of eyes according to refractive error in various types of amblyopia $(\mathbf{n}=91)$.

\begin{tabular}{|c|c|c|c|c|}
\hline Diagnosis & $\begin{array}{c}\text { AsH/H } \\
\text { (\% of eyes) }\end{array}$ & $\begin{array}{l}\text { AsMy/My } \\
\text { (\% of eyes) }\end{array}$ & $\begin{array}{c}\text { AsMix } \\
\text { (\% of eyes) }\end{array}$ & $\begin{array}{c}\text { Chi Square } \\
\text { (P value) }\end{array}$ \\
\hline Strabismic Amblyopia $(n=36)$ & $19(52.77 \%)$ & $12(33.33 \%)$ & $5(13.88 \%)$ & $\begin{array}{c}8.16 \\
(0.016)^{*}\end{array}$ \\
\hline $\begin{array}{l}\text { Anisometropic Amblyopia } \\
(n=37)\end{array}$ & $20(54.05 \%)$ & $12(32.43 \%)$ & $5(13.51 \%)$ & $\begin{array}{c}9.13 \\
(0.010)^{*}\end{array}$ \\
\hline Isometropic Amblyopia $(n=18)$ & $12(66.66 \%)$ & $4(22.22 \%)$ & $2(11.11 \%)$ & $\begin{array}{c}9.33 \\
(0.009)^{*}\end{array}$ \\
\hline Total $(n=91)$ & $51(56.04 \%)$ & $28(30.76 \%)$ & $12(13.18 \%)$ & $\begin{array}{c}25.34 \\
(0.001)^{*}\end{array}$ \\
\hline
\end{tabular}

$* \mathrm{P}<0.05$, Significant

Table 9 shows the distribution of eyes according to the refractive error. Most eyes were found to have hyperopic astigmatism/ hyperopia (56\%) followed by myopic astigmatism/myopia (31\%) while mixed astigmatism was least common (13\%).

Note: In patients with cataract having stimulus deprivation amblyopia, retinoscopy was not possible due to hazy media.

$\mathbf{A s H} / \mathbf{H}=$ hyperopic astigmatism/hyperopia; $\mathbf{A s M y} / \mathbf{M y}=$ myopic astigmatism/myopia; $\mathbf{A s M i x}=$ mixed astigmatism $($ Table- 8$)$.

Table-9: Showing the distribution of eyes according to contrast sensitivity $(n=100)$

\begin{tabular}{|c|c|c|}
\hline Contrast Sensitivity & No. of eyes & Percentage (\%) \\
\hline $0.00-0.15$ & 38 & 38.00 \\
\hline $0.30-0.45$ & 16 & 16.00 \\
\hline $0.60-0.75$ & 9 & 9.00 \\
\hline $0.90-1.05$ & 13 & 13.00 \\
\hline $1.20-1.35$ & 20 & 20.00 \\
\hline $1.50-1.65$ & 4 & 4.00 \\
\hline $1.80-1.95$ & 0 & 0.00 \\
\hline $2.10-2.25$ & 0 & 0.00 \\
\hline Total & 100 & 100.00 \\
\hline
\end{tabular}




\section{Original Research Article}

The contrast sensitivity of the eyes in the present study was divided into eight groups. Maximum numbers of eyes were seen with $0.00-0.15$ contrast sensitivity (Table- 9 ).

Table-10: Average contrast sensitivity in various types of amblyopia $(n=100)$

\begin{tabular}{|c|c|c|c|}
\hline Diagnosis & $\begin{array}{c}\text { Contrast Sensitivity } \\
(\text { Mean } \pm \text { SD })\end{array}$ & F value & $P$ value \\
\hline Strabismic Amblyopia $(n=36)$ & $0.58 \pm 0.45$ & \multirow{4}{*}{1.296} & \multirow{4}{*}{$0.280 *$} \\
\hline Anisometropic Amblyopia $(\mathrm{n}=37)$ & $0.56 \pm 0.53$ & & \\
\hline Isometropic Amblyopia $(\mathrm{n}=18)$ & $0.79 \pm 0.52$ & & \\
\hline Stimulus Deprivation Amblyopia $(\mathrm{n}=9)$ & $0.40 \pm 0.53$ & & \\
\hline
\end{tabular}

$* \mathrm{P}>0.05$, Non-significant

The contrast sensitivity of all eyes included in the present study was taken and the average contrast sensitivity in each group was determined (Table -10).

Table-11: Distribution of patients with normal and abnormal stereopsis in various types of amblyopia (n=91).

\begin{tabular}{|c|c|c|c|}
\hline Diagnosis & $\begin{array}{c}\text { Patients with normal } \\
\text { stereopsis } \\
\text { (\% of patients }) \\
\end{array}$ & $\begin{array}{c}\text { Patients with abnormal } \\
\text { stereopsis } \\
(\% \text { of patients })\end{array}$ & $\begin{array}{c}\text { Chi Square } \\
\text { (P Value) }\end{array}$ \\
\hline Strabismic amblyopia $(n=36)$ & $15(41.66 \%)$ & $21(58.33 \%)$ & $\begin{array}{c}1.00 \\
(0.31)^{*}\end{array}$ \\
\hline Anisometropic amblyopia $(n=37)$ & $17(45.94 \%)$ & $20(54.05 \%)$ & $\begin{array}{c}0.24 \\
(0.62)^{*}\end{array}$ \\
\hline Isometropic amblyopia $(n=9)$ & $3(33.33 \%)$ & $6(66.66 \%)$ & $\begin{array}{c}1.00 \\
(0.31)^{*}\end{array}$ \\
\hline Stimulus deprivation amblyopia $(n=9)$ & $4(44.44 \%)$ & $5(55.55 \%)$ & $\begin{array}{c}0.11 \\
(0.74)^{*}\end{array}$ \\
\hline Total $(n=91)$ & $39(42.85 \%)$ & $52(57.14 \%)$ & $\begin{array}{c}1.85 \\
(0.17)^{*}\end{array}$ \\
\hline
\end{tabular}

*P>0.05, Non-Significant

The stereopsis was tested and the patients were divided into normal and abnormal groups. Out of these $43 \%$ had normal while $57 \%$ had abnormal stereopsis (Table-11).

Table-12: Distribution of eyes with normal and abnormal fine motor skills in various types of amblyopia (n=100).

\begin{tabular}{|c|c|c|c|}
\hline Diagnosis & $\begin{array}{c}\text { Eyes with normal } \\
\text { fine motor skills } \\
\text { (\% of eyes) }\end{array}$ & $\begin{array}{c}\text { Eyes with abnormal } \\
\text { fine motor skills } \\
\text { (\% of eyes) }\end{array}$ & $\begin{array}{c}\text { Chi Square } \\
\text { (P Value) }\end{array}$ \\
\hline Strabismic amblyopia $(n=36)$ & $11(30.55 \%)$ & $25(69.44 \%)$ & $\begin{array}{c}5.44 \\
(0.01)^{*}\end{array}$ \\
\hline $\begin{array}{l}\text { Anisometropic amblyopia } \\
(\mathrm{n}=37)\end{array}$ & $19(51.35 \%)$ & $18(48.64 \%)$ & $\begin{array}{c}0.03 \\
(0.86) \#\end{array}$ \\
\hline Isometropic amblyopia $(\mathrm{n}=18)$ & $14(77.77 \%)$ & $4(22.22 \%)$ & $\begin{array}{c}5.55 \\
(0.01)^{*}\end{array}$ \\
\hline $\begin{array}{l}\text { Stimulus deprivation amblyopia } \\
(\mathrm{n}=9)\end{array}$ & $6(66.66 \%)$ & $3(33.33 \%)$ & $\begin{array}{c}1.00 \\
(0.31) \#\end{array}$ \\
\hline Total $(n=100)$ & $50(50 \%)$ & $50(50 \%)$ & \\
\hline
\end{tabular}

$* \mathrm{P}<0.05$, Significant, $\# \mathrm{P}>0.05$, Non-Significant

The fine motor skills were tested and the eyes were divided into normal and abnormal groups according to the accuracy of shape reproduction. Out of these $50 \%$ of eyes had normal and the rest (50\%) had abnormal fine motor skills (Table-12). 
Original Research Article

Table-13: Correlation between the various visual deficits and type of amblyopia.

\begin{tabular}{|l|c|c|c|c|c|c|c|}
\hline & $\begin{array}{c}\text { Visual } \\
\text { acuity } \\
\text { (\% of eyes) }\end{array}$ & $\begin{array}{c}\text { Contrast } \\
\text { sensitivity } \\
\text { (\% of eyes) }\end{array}$ & $\begin{array}{c}\text { Stereopsis } \\
\text { (\% of } \\
\text { patients) }\end{array}$ & $\begin{array}{c}\text { Fine motor } \\
\text { skills (\% } \\
\text { of eyes) }\end{array}$ & $\begin{array}{c}\text { Color } \\
\text { vision (\% } \\
\text { of eyes) }\end{array}$ & $\begin{array}{c}\text { Crowding } \\
\text { phenomenon } \\
\text { (\% of eyes) }\end{array}$ & $\begin{array}{c}\text { Refractive } \\
\text { Error } \\
\text { (\% of eyes) }\end{array}$ \\
\hline $\begin{array}{l}\text { Strabismic } \\
\text { amblyopia }\end{array}$ & 75.00 & 63.88 & 58.33 & 69.44 & 0 & 63.38 & 100 \\
\hline $\begin{array}{l}\text { Anisometropic } \\
\text { amblyopia }\end{array}$ & 62.16 & 59.45 & 54.05 & 48.64 & 0 & 35.14 & 100 \\
\hline $\begin{array}{l}\text { Isometropic } \\
\text { amblyopia }\end{array}$ & 55.55 & 55.55 & 66.66 & 22.22 & 0 & 33.33 & 100 \\
\hline $\begin{array}{l}\text { Stimulus } \\
\text { deprivation } \\
\text { amblyopia }\end{array}$ & 88.88 & 66.66 & 55.55 & 33.33 & 0 & 55.55 & N/A* \\
\hline
\end{tabular}

*N/A - not applicable

Shows correlation between the various visual deficits and the type of amblyopia.

In patients with cataract having stimulus deprivation amblyopia, retinoscopy was not possible due to hazy media (Table-13).

\section{Discussion}

In India, amblyopia affects approximately one to four percent of children [3]. It is the most common cause of monocular vision loss in population under 40 years, accounting for more cases than trauma and all other causes combined [4]. The conditions leading to functional amblyopia include strabismus, anisometropia, astigmatism, hypermetropia, cataract, and other forms of stimulus deprivation.

The definition of amblyopia solely depends on visual acuity; it does not take into account the qualitative differences in vision that amblyopes often experience resulting in poorer vision than that reflected by measured Snellen's acuity [2].

A large number of children in rural India are yet to enroll or suffer from early drop out. The main reason for this is of course poverty but another important yet neglected reason is their inability to learn at school. According to another study done by Janti et al, $32.76 \%$ children in urban area suffer from amblyopia while the percentage is $67.21 \%$ in rural area [5]. This is because of the lack of awareness among the rural population to have regular eye check-up. Thus screening of children from rural area is of utmost importance as patients with amblyopia have higher chances of becoming blind or to become visually impaired in later life [6].

The mean age was $15.00 \pm 5.74$ years. Most of the patients were already in middle school by the time they presented to us. This probably accounted for the relatively late hospital presentation of these patients and thus higher mean age. Majority of patients were male $-56 \%$ and remaining were females $-44 \%$. The male to female ratio in the study group was 1.34:1. The demographic findings of the present study were in line with the literature. Similar to the present study, the majority patients were male. In the study by Menon V. et al., carried out on 733 eyes of 683 patients, majority were males $373(54.61 \%)$ as compared to females $310(45.38 \%)$ [7].

Type of Amblyopia- Majority of the patients were found to have anisometropic amblyopia (37\%) and strabismic amblyopia (36\%). These two types comprised more than $70 \%$ of the study population. The data was found to be statistically significant.

The findings of the present study were almost similar with the study by Dorn et al., carried out on 434 patients, which showed strabismic amblyopia to be present in $35 \%$ patients while anisometropic amblyopia was present in $22.6 \%$ [8]. In another study by Menon V. et al., strabismic amblyopia was present in $37.88 \%$; anisometropic amblyopia in $22.1 \%$, isometropic amblyopia in $12.88 \%$ and $7.63 \%$ had stimulus deprivation amblyopia [7]. The visual acuity was tested by using the LogMAR chart with maximum number of patients having visual acuity between $0.5-1.0$ LogMAR units accounting for almost $84 \%$ of the total sample size. F test was applied to the average visual acuity and the data was found to be statistically significant.

The average visual acuity between the various types of amblyopia was compared with each other and the data was found to be statistically significant except between strabismic and stimulus deprivation amblyopia; and between anisometropic and isometropic amblyopia which 
was found to be statistically non-significant. In a study by Menon V. et al., the authors found $52.25 \%$ patients with visual acuity between 0.3-0.6 LogMAR units and 31.24\% patients between 0.7-1.0 LogMAR units. $16.50 \%$ patients had a visual acuity of $<1.0$ LogMAR units [7]. The average visual acuity was better for patients with anisometropic amblyopia as compared to strabismic amblyopia. Also patients with isometropic amblyopia showed a better visual acuity, while those with stimulus deprivation amblyopia had the worst visual acuity. This is in accordance with the literature [9].

Colour Vision- The colour vision was found to be normal in all 100 eyes of 91 patients enrolled in the study. Our result matches best with study by Bradley A. et at. who compared colour and luminance discrimination in amblyopia in six normal and six amblyopic subjects. According to them the color discrimination appeared normal in amblyopia when measured with standard tests but however there was luminance discrimination [10]. The earlier studies had suggested that colour vision may have been normal in amblyopia indicated; therefore, that amblyopia might selectively affect only that subset of neurons responsible for detecting luminance differences $[11,12,13,14]$.

In another study by Kathy T. Mullen et al., which compared colour and luminance vision in human amblyopia, all subjects had normal colour vision [15].

Crowding Phenomenon- Presence or absence of crowding phenomenon was tested by checking for any improvement in the single letter visual acuity as compared to the normal visual acuity by means of LOGMAR chart. Presence of crowding was found more in strabismic amblyopia as compared to the other types of amblyopia and the data was found to be statistically non-significant.

In a study by Y.S. Bonneh et al., who studied local and nonlocal deficits in amblyopia: acuity and spatial interactions on 60 subjects, it was found that a strabismic patient, who had almost normal acuity for a single optotype but very poor acuity for multiple patterns. Also, the strabismic patient showed a twofold more crowding as compared to a patient with anisometropic amblyopia [16]. In another study by Levi \& Klein, 1985, they concluded that the crowding effect in strabismics, unlike in anisometropes, is larger than their acuity deficit would predict [17].

Refractive Error- The refractive status of the amblyopic eyes was categorized as hyperopic astigmatism/ hyperopia; myopic astigmatism/myopia and mixed astigmatism. Most eyes were found to have to hyperopic astigmatism/ hyperopia $(56.04 \%)$ followed by myopic astigmatism/ myopia $(30.76 \%)$ and least had mixed astigmatism

\section{Original Research Article}

(13.18\%). The distribution of eyes according to refractive error in the study group showed statistical significance. The results of the present study matches best with the study conducted by Menon V. et al. who conducted a study on 733 eyes of 683 patients who conducted a prospective hospital based observational study to evaluate the clinical profile of patients with amblyopia. In their study $52.25 \%$ had hypermetropia while $33.95 \%$ had myopia [9]. In another study by Dorn et al., carried out on 434 patients, the distribution of refractive error showed the greatest number of hyperopic astigmatism/hyperopia (50\%), followed by myopic astigmatism/ myopia (35.71\%), and mixed astigmatism (12.24\%) [18].

Contrast sensitivity- Several studies have shown that there are discrepancies in contrast sensitivity function (CSF) obtained in strabismic or anisometropic amblyopia. Strabismic amblyopia is generally characterized by a highfrequency decrease in the CSF, while the CSFs of anisometropic patients are affected at all spatial frequencies. A difference in the apparent supra threshold contrast between the two groups has also been reported.

In strabismic patients the maximum point of the CSF is relatively uncorrelated with the visual acuity level. Even when the visual acuity is markedly reduced, the CSF curve is essentially normal from low frequencies to the maximum point, while the steepness of the high-frequency limb varies. The anisometropic amblyopes generally has a CSF that is subnormal at all spatial frequencies. It is observed that contrast sensitivity deficit was found more in strabismic (63.88\%) and anisometropic (59.45\%) amblyopia. The average contrast sensitivity between the various types of amblyopia was compared and the data was found to be statistically non-significant.

Our result matches best with the study conducted by $\mathrm{M}$ Abrahamsson et al [19] who studied ten patients with strabismic amblyopia and 13 patients with anisometropic amblyopia together with 20 controls in which the visual acuity and contrast sensitivity were measured and compared.

Stereopsis- Many amblyopes have little or no stereopsis, the functional significance of which has rarely been reported [20]. Most studies that have investigated this observation have compared performance under monocular and binocular conditions $[21,22]$ generally concluding that binocular vision facilitates control of manipulation, reaching and balance [22] and that people who lack stereopsis have difficulty in performing tasks that rely on three dimensional visual cues [23]. There are, however, many individuals who perform well on tests of manual dexterity even though their stereopsis is poor. The results of the present study, that stereopsis is reduced in about $57.14 \%$ 


\section{Original Research Article}

of patients was comparable with the study by Webber et al [24] and the data was found to be statistically nonsignificant.

Fine motor skills- In the present study, fine motor skills were reduced, particularly in those with strabismic amblyopia. the result was statistically significant for strabismic and isometropic amblyopia while it was nonsignificant for anisometropic and stimulus deprivation amblyopia. This is in accordance with the literature. In a study by Webber et al., they found that the etiology of amblyopia could influence performance on fine motor skills tasks due to hypothesized differences in visual neural development between those with a history of blur and those with a history of ocular misalignment and they found significant differences in performance between subgroups and that not all amblyopia groups displayed a deficit in fine motor skills [24].

\section{Correlation between the various visual deficits and type of Amblyopia}

In the present study, the visual acuity was noted to be most depressed in stimulus deprivation amblyopia (88.88\% of eyes) followed by strabismic amblyopia (75\% of eyes) [25]. The contrast sensitivity function was shown to be almost equally affected in all the amblyopic eyes. The stereopsis was observed to be absent in more than $50 \%$ patients in all types of amblyopia though the difference of percentage within the groups was insignificant. Fine motor skills were maximally affected in eyes with strabismic amblyopia (69.44\%) followed by anisometropic amblyopia (48.64\%). Colour vision was not affected in any type of amblyopia. Crowding phenomenon was observed in $63.38 \%$ eyes with strabismic amblyopia followed by $55.55 \%$ eyes with stimulus deprivation amblyopia. Refractive errors were found in all types of amblyopia except stimulus deprivation amblyopia where retinoscopy was not possible due to hazy media.

Another important factor that this study reveals relatively older ages of presentation to a specialty clinic irrespective of the sub-type of amblyopia present. Seven to 8 years is the critical time after which therapeutic measures for the treatment of amblyopia become less effective [26]. This reiterates that efforts to screen patients for amblyopia and educate personnel at every level to suspect, diagnose, treat or refer the patient as soon as possible.

\section{Limitations of the study}

1. Large sample size is required to establish any fact, which is the drawback of the present study as there was a limitation of a study duration.

2. No correlation between type of amblyopia and age of presentation was studied.

\section{Conclusion}

1. Amblyopia and associated strabismus can have devastating psychosocial and economic fall-outs. Failure to develop binocular vision and unilateral or bilateral visual impairment may prevent the individual from pursuing certain occupations.

2. Knowledge about the sub-types of amblyopia is important because the clinical presentations, management and outcomes of these different types are different. The data in the present study could be used to enhance screening efforts in an organized manner.

3. Population-based studies at a future date would be useful to further validate the mass education measures that can be taken up to prevent and treat this condition.

\section{What this study adds to existing knowledge?}

There is a scarcity of studies on the current topic specially in rural tertiary set-up. This study is providing a good insight not only on visual acuity but other component of vision in amblyopia cases in the current study area.

\section{Author's contribution}

Dr. Somya Dulani: Concept of the study, data collection, data analysis, manuscript writing, critical analysis.

Dr. Sachin Diagavane: Concept of the study, data analysis, manuscript writing, critical analysis.

Dr. Anand Tibewal: Data collection, data analysis, manuscript writing.

Funding: No funding sources

Conflict of interest: None declared

Ethical Approval: This study was approved by the Institutional Ethics Committee

\section{References}

1. Dadeya S, Khurana C. Diagnosis and Treatment of Childhood Amblyopia.AIOS CME series (No.18).

2. Von Noorden GK. Mechanism of amblyopia: Doc Ophthalmol.1977;34:93.

3. Vijayalakshmi P, Panadikar R. Classification of amblyopia. Strabisscope. 1996;3:6-7.

4. Repka MX, Lee KA, Melia M. American Academy of Ophthalmology amblyopia preferred practice pattern ${ }^{\circledR}$. November 2017.

5. Janti SS, Raja AM, Matheen A, Charanya C, Pandurangan R. A cross sectional study on prevalence of amblyopia in school going children. J Evol Med Dent Sci. 2014; 3(30):8561-8565. doi: 10.14260/jemds/2014/3086. 
6. Scott WE, Kutschke PJ, Keech RV, Pfeifer WL, Nichols B, Zhang L. Amblyopia Treatment Outcomes. J AAPOS. 2005; 9 (2):107-111. doi: https://doi.org/10.1016/j. jaapos. 2004.12.003.

7. Von Noorden GK. Classification of amblyopia. Am J Ophthalmol 1967;63(2):238-244. doi: https://doi.org/ 10. 1016/ 0002-9394(67)91543-7.

8. Li S, Zou H, Wei C. Stereoscopic visual acuity in types of ametropic amblyopia in children. J Pediatr Ophthalmol Strabis. 2014;51(2):105-110. doi: https://doi.org/10.3928/ 01913913-20140220-04.

9. Menon V, Chaudhuri Z, Saxena R, Gill K, Sachdev MM. Profile of amblyopia in a hospital referral practice. Indian J Ophthalmol.2005;53(4):227-234. doi: 10.4103/0301-4738. 18903.

10. Bradley A, Dahlman C, Switkes E, De Valois K. A comparison of color and luminance discrimination in amblyopia. Invest Ophthalmol Vis Sci.1986;27(9):14041419.

11. François J, Verriest G: La discrimination chromatique dans l'amblyopiestrabique. Doc Ophthalmol.1967; 23(1): 318-323. doi:10.1007/BF02550754.

12. Roth A: Le senschromatique dans amblyopiefonctionelle. Doc. Ophthalmol.1968;24:113-200. doi:10. 1007/ BF02550949.

13. Lumbroso BD and Proto F: The anomalies of the sensorchromaticone are subjected to biopsy with eccentric fixation. Eye Bulletin. 1963;42:699.

14. Marre $\mathrm{M}$ and Marre E: Color vision in squint amblyopia. Mod Probl Ophthalmol.1978;19:308-313.

15. Mullen KT, Sankeralli MJ, Hess RF. Color and luminance vision in human amblyopia: shifts in isoluminance, contrast sensitivity losses, and positional deficits. Vision Res.1996; 36(5):645-653. doi:10.1016/ 0042-6989 (95)00159-X.

\section{Original Research Article}

16. Bonneh YS, Sagi D, Polat U. Local and non-local deficits in amblyopia: acuity and spatial interactions. Vision Res. 2004;44(27):3099-3110. doi: https://doi.org/10.1016/j. visres. 2004. 07.031.

17. Levi DM, Klein SA. Vernier acuity, crowding and amblyopia. Vision Res.1985;25(7):979-91. doi: https://doi. org/ 10.1016/0042-6989(85)90208-1.

18. Dorn L, Petrinović-Dorešić J. Stereoscopic visual acuity in different types of amblyopia. Acta clinica Croatica. 2007;46(1-Supplement 1):63-70.

19. Abrahamsson M, Sjöstrand J. Contrast sensitivity and acuity relationship in strabismic and anisometropic amblyopia. Br J Ophthalmol.1988;72(1): 44-49. doi: 10. 1136 / bjo. 72.1 .44 .

20. Fielder AR, Moseley MJ. Does stereopsis matter in humans? Eye.1996; 10(2): 233-238. doi: 10.1038/eye. 1996.51.

21. Joy S, Davis H, Buckley D. Is stereopsis linked to handeye coordination? Br Orthoptic J. 2001;58:38-41.

22. Jones RK, Lee DN. Why two eyes are better than one: the two views on binocular vision. J Exp Psychol.1981;7(1): $30-40$.

23. Murdoch JR, McGhee CN, Glover V. The relationship between stereopsis and fine manual dexterity: pilot study of a new instrument. Eye 1991;5(5):642-643. doi:10.1038/eye. 1991.112.

24. Webber AL, Wood JM, Gole GA, Brown B. The effect of amblyopia on fine motor skills in children. Invest Ophthalmol Vis Sci.2008;49(2):594-603. doi: 10.1167/ iovs. 07-0869.

25.International Council of Ophthalmology. Visual Acuity Measurement Standard. Available at http://www.icoph.org/ resources/47/Visual-Acuity-Measurement-Standard.html. 26. Woodruff G, Hiscox F, Thompson JR, Smith LK. Factors affecting the outcome of children treated for amblyopia. Eye. 1994;8(6):627-631. doi:10.1038/eye.1994. 157.

\section{How to cite this article?}

Dulani S, Diagavane S, Tibewal A. Evaluation of visual deficits in different types of amblyopia at rural tertiary setup. . Trop J Ophthalmol Otolaryngol.2019;4(8):478-487.doi:10.17511/jooo.2019.i08.05 